\title{
29 \\ A BUSINESS MODEL FOR MANAGING THE VIRTUAL ENTERPRISE
}

\author{
David Walters \\ Professor of Management, Sydney Graduate School of Management, NSW, AUSTRALIA \\ d.walters@uws.edu.au
}

\begin{abstract}
Conceptually the virtual enterprise has much to offer. The notion that asset utilisation can be improved by working within an optimally designed and balanced organisation with each member contributing specific processes, capabilities as well as assets, capable of realising customer product and service expectations cost-effectively is now a reality. However, there is a need for a business model that can be used for planning and managing the performance of this organisation that, unlike the traditional organisation, has a number of "partner stakeholders" to satisfy. This paper considers how the strategic and operational processes of the virtual organisation can be both planned and managed.
\end{abstract}

\section{INTRODUCTION}

New business models are constantly emerging, ones in which competitive advantage is based upon managing processes that facilitate rapid and flexible responses to 'market' change, and ones in which new capabilities are based upon developing unique relationships with partners (suppliers, customers, employees, shareholders, government and, often, with competitors). Normann (2001) discusses "a new strategic logic". He suggests that managers need to be good at mobilizing and managing resources rather than owning them. The value chain/virtual enterprise model has three primary management tasks in the process of integrating value strategy and value delivery. Customer value opportunities are identified, value production processes are coordinated and, provided that partners' objectives can be met, customer value is delivered. The model is a structure of networks between value producers and customers: if it is to be successful, then an understanding and an acceptance of tasks, roles, responsibilities and accountabilities is necessary. It is the role of value chain management to coordinate the network between and among the virtual enterprise/value chain producers and the customer.

\section{A REVIEW OF STRATEGY, OPERATIONS AND STRUCTURE}

Three major differences are suggested. The first concerns the emphasis on performance. Currently many organisations emphasise cost-led efficiency as a primary objective. Not only is this constraining it may not to be in the shareholders' 
interests: cost reductions typically have a negative impact on customer service and this, in turn, has the same impact on revenues. The second change involves a switch from an internal focus in which assets and resources must be owned to one of cooperation and collaboration in which assets and resources are managed. The third shift is one in which the organisation becomes proactive in its operations in for both customer and supply markets

This notion can be expanded. The role of the entrepreneur (McHugh et al's coordinator) is to balance the allocation of resources between transformation inputs and interaction inputs. Central to the decision is not who owns the inputs but rather how they may be incorporated into the business organisation and how this then is structured to ensure that customer and stakeholder expectations may be met. Organisation structures are changing alongside the changes in managerial philosophy. An organisation requires a structure within which strategy, once decided, may be evolved, evaluated and decided upon. An effective value strategy focuses on value creation for customers using innovation in the design, production, marketing, and delivery and servicing components of value. A "value-led" strategy should become proactive rather than be reactive.

\section{STRUCTURAL ALTERNATIVES TO MEET CUSTOMER EXPECTATIONS: TIME, COST, PERFORMANCE AND RISK}

Because the virtual enterprise comprises a number of organisations the interorganisational nature of performance delivery and expectations must be identified from the very start. Neely et al (2002) comment:

"Organizations achieve their defined objectives - that is, they perform - by satisfying their stakeholders' and their own wants and needs with greater efficiency and effectiveness than their competitors"

Neely et al (op cit) suggest five criteria that any performance measurement approach should address:

- A clear understanding of whom the stakeholders are and what they require

- A clear articulation of what the organisation requires from its stakeholders.

- Strategies that reflect the interests of all participants.

-Processes that are in place to ensure the "organization" can implement its strategies.

- Capabilities that facilitate the operations of the processes.

Stakeholders have become partners, and their requirements and their contributions become as central to the success of the "organization" as are those of the coordinator who may initiate the structure.

Campbell's (1996) typology of virtual organizations brings out some important structural differences that impact on performance outcomes:

Internal virtual organisations: autonomous business units are formed within a large organization: “...to provide operational synergies and tailor responses to specific customer demands". 
Stable virtual organisations: these are conventionally structured organizations that outsource non-core activities to a small network of suppliers whose processes and activities become integrated with the initiator.

Dynamic virtual organisations: organizations that focus on core capabilities and introduce external partners in cooperative ventures.

Agile virtual organisations: temporary networks that are rapidly formed: “...to exploit new market opportunities through the mutual exchange of skills and resources".

It is interesting to note three points. First, the typology identifies a progressive move towards a structure built around "intangibles" and second, it reflects an increasing confidence of these organisations managing process, knowledge, technology and relationship applications. The third point concerns the ability to match structure with risk. For example, internal virtual organisations can manage low risk situations such as brand leverage accompanying an extension of a product range. They can also meet customers' expectations such as customization and quality. However, product differentiation required to meet the expectations of a small segment of a large market may be best realised by a stable virtual organisation. For unrelated product-market developments, developments requiring additional expertise dynamic virtual organisations offer a suitable structure. An agile virtual organisation may prove to be more suited where there is a requirement for short order cycle time management and flexible order quantities such as those often found in the 'fashion' segments of apparel markets.

\section{THE NOTION OF CRITICAL INDUSTRY SUCCESS FACTORS: (A “MACRO” PERSPECTIVE)}

In every industry sector there are usually one or more factors that create advantage for organisations that can identify and exploit them. The "new economy" has introduced new concepts and new philosophies that are changing the way strategic decisions are made. It focuses attention on aspects of management that underwrite success; in many respects these are not new, rather they are new ways of using existing skills and resources. We would suggest they offer opportunities to create competitive advantage in more innovative ways, including structures used to undertake them. Industry Success Drivers work at a "macro" level of decision making in a response to strategic opportunities and/or threats. Thus, it is suggested that competitive advantage is derived from four principle areas:

Process management: effective organisations now view process management as a means to work together to identify core processes across the industry demand and supply chains. They explore the implications of locating these core processes within specialist, partnership organisations.

Knowledge management: the organisational capability that identifies, locates (creates or acquires), transfers, converts and distributes knowledge to convert into competitive advantage

Technology management: is the integration of process and product technology to address the planning, development and implementation of technological capabilities and capacities to meet the strategic and operational objectives of an organisation or combination of organisations. 
Relationship management: is the managerial activity which identifies, establishes, maintains and reinforces economic relationships with customers, suppliers and other partners with complementary (and supplementary) capabilities and capacities so that the objectives of the organisation and those of all other partners may be met by agreeing and implementing mutually acceptable strategies.

For example, consider the pharmaceutical industry and the computer hardware and software industries and ask what it is that delivers competitive advantage: then consider what it was that used to drive them. In the pharmaceutical industry, the primary driver was knowledge located in $\mathrm{R}$ and $\mathrm{D}$ programmes. Currently the average ROI is some six percent and, clearly, for the majority of investors this is an unsatisfactory return. Many of the large "pharmas" are using specialists to undertake the R\&D role while they investment in processes and capabilities (such as manufacturing and marketing) that reinforce their strategic positioning (and therefore) competitive advantage. It could be argued that the important industry success drivers are becoming process and relationship based, the ability to meet high levels of performance have become critical as value generation has migrated. Mark Levin CEO, Millennium (Champion: 2001) described how the value production and delivery in the pharmaceutical industry is changing.

The computer industry is another example with chip manufacturing; computer assembly and delivery, software and support services are now all quite independently distinguishable but interlinked markets. Where once IBM was dominant across the whole industry, Intel, Dell and Microsoft now coexist as a virtual enterprise/value chain model.

In computing, organisations have built strong reputations based upon industry success drivers of innovation (knowledge management based) supported by high quality and reliability (process management based), and customer service support accessed through distributor networks (relationship management based). The IBM business model of the 1970s and early 1980s lost ground to organisations that identified new strategic value drivers (or modifications of the existing characteristics) and therefore, new ways of competing. For example, Dell's innovation was to develop strong inter dependencies with suppliers and "direct" relationships and communications with customers, offering them the opportunity to "design or configure" their own product, also offering a short order cycle time. Dell made an impact on both the small and large PC user markets. This was reinforced by the strong relationships developed with suppliers. Rather than add capacity to an already over capacity components market, Dell became a customer rather than a competitor of companies such as Sony.

\section{THE NOTION OF CUSTOMER AND STAKEHOLDER VALUE DRIVERS: A ("MICRO" PERSPECTIVE)}

Customers consider both the benefits they seek and receive from products and services they purchase, when they are purchased and during the life of the product. Best (2004). MacMillan and McGrath (1997) argue that the customer life cycle, or the consumption chain is a means by which suppliers ".. can uncover opportunities to position their offerings in ways that they, and their competitors, would never have thought possible". Using a mapping process they capture the customer's total 
experience with a product or service thus identifying numerous ways in which value can be added to a product or service. In the process consumers answer a series of questions to establish behaviour occurring from awareness of a "need", evaluation, purchasing, product/service use and eventual disposal. From these, and other contributions, it follows that both generic and product-market specific customer value drivers are important considerations. From four generic value drivers specific value drivers are developed:

Performance: products and services that fulfil more customer expectations than competitors.

Time: an ability to 'commercialise' innovations that provide customer effective solutions is one aspect of time as a value driver. The other is the ability to provide 'quick response' solutions to routine customer order management.

Cost Management: the effective use of relevant aspects of 'value production economies' such as specialisation, location (clusters), experience, as well as scale and scope.

Risk Reduction: reducing the level of risk, or dispersing risk across a number of partners clearly has attraction.

\section{Stakeholder Expectations}

Stakeholder expectations share four common features:

A return on their "investment: typically measured as economic cash flow, share price appreciation and dividend growth

Profitability: measured as a "margin" on current and future sales activities

Productivity: performance of the asset base - specifically to maintaining a low asset base and, therefore, high asset utilisation together with low working capital commitments

Growth: particularly comparison growth rates between the stakeholder's own business and those of other partners and the "market" and a comparison with competitor growth rates.

\section{THE "MACRO"/ "MICRO" INTERFACE: DEVELOPING A RELEVANT BUT EXCLUSIVE BUSINESS MODEL}

An important and obvious question is how the strategic decisions are implemented and relate to operational activities. Magretta (2002) suggests: " a successful business model represents a better way than the existing alternatives. It may offer more value to a discrete group of customers. Or it may completely replace the old way of doing things and become the standard for the next generation of entrepreneurs to beat”, adding substance with:“... all new business models are variations on the generic models underlying all businesses.... activities associated with making something ... activities associated with selling something ...A new business model's plot may turn on designing a new product for an unmet need. Or it may turn on a process innovation, a better way of making or selling or distributing an already proven product or service".

Magretta cites Dell as a company that has created a powerful business model by identifying virtual organisation processes that it would do and identifying partners to 
undertake those processes it cannot, or would prefer not to, do. In this way Dell, by selling directly to end-users, has the vital information necessary to manage inventory better than its competitors and avoids the high costs of holding inventory and the very high cost of obsolescence due to the rapid application of technology. Equally by working with "well-known" suppliers Dell creates additional value for the customers by incorporating branded components in its products thereby offering "guaranteed" performance for the overall product proposition.

This example identifies an essential issue concerning the difference between value added and added value. Added value is an accounting concept. Essentially it identifies the difference between outputs and the inputs used to generate them in accounting terms. As such it offered a means of comparing relative corporate efficiency performances. Kay (1993) used the concept to develop a strategic measure of competitive advantage, suggesting that if "capital costs" are "comprehensively calculated" and, together with operating costs, deducted from revenues, a measure of competitive advantage can be derived. It is interesting to note that subsequently Stern Stewart introduced EVA (Economic Value Added) as a measure of corporate efficiency in creating shareholder value. Positive shareholder value is generated when operating profit exceeds operating costs and (comprehensive) capital costs. Clearly if this does not occur then value is destroyed.

Magretta's approach is different, taking qualitative context and then converting this into a quantitative value. Making customers and partners more competitive by offering value propositions that add value to their business models is a source of competitive advantage. For example, a packaging manufacturer who considers the customer's customer may well create competitive advantage for both organisations by taking the trouble to understand the end-user customer's uses and preferences. A preference for convenience and the willingness to pay extra for ring-pull cans offers both the packaging producer and the food producer opportunity. Understanding the processes and costs of a $\mathrm{B} 2 \mathrm{~B}$ customer may enable a supplier to deliver materials or components in a format that offer these customers significant cost reductions. The simple but very effective example given by Shank and Govindarajan (1993) is an excellent case of how a supplier creates value added for a chocolate processor by supplying chocolate in bulk liquid form rather than the solid bars. Both supplier and customer benefited: the customer no longer had to unpack and melt the chocolate bars while the supplier eliminated the cost of moulding bars and packing them. Source (Hergert and Morris :1989).

In the emerging "New Economy" traditional hierarchical models that deploy everincreasing amounts of capital to achieve market dominance through large-scale virtual or horizontal market integration are unlikely to be flexible or adaptable enough. While size still matters and it is not suggested that the large "corporates" are yet heading the way of the dinosaur, traditional models require re-examination. In particular it is suggested that the "new economy firm" should focus on four key attributes in developing and designing their business models. These components are interdependent sustainable competitive advantage is achieved when both customer and stakeholder satisfaction is realised. It also represents the point in the planning process at which the macro and micro processes interface: strategic and customer value drivers are incorporated into the design of an effective and efficient business model: 
Free cash flow generated is a primary performance requirement. Given the assumption that the primary objective of the organization is to generate (and maximise) free cash flow (albeit within legal, social and corporate imposed constraints) the ultimate, comparative, performance model will be the net present value (NPV) of the free cash flow generated.

Identify and Structure an Organisation Based upon Critical Industry Success Drivers: Determine the important" industry characteristics" required for sustainable competitive advantage decide where the value offer is to be positioned in the 'market' to create stakeholder value and competitive advantage. Influential in this will be the ways in which the customer value drivers (time, cost, performance and risk) may be met efficiently and, at the same time, achieve sustainable competitive advantage. From this it follows mat:

"Value" and "ownership" of the asset base is important: While asset leverage is an attractive strategic planning alternative, there are potential negative considerations. One concern is control. An asset upon which an organisation is dependant, but is controlled by a partner, can create difficulties if it poses supply continuity problems. Clearly there are solutions. Acquisition is one alternative but this contradicts the ethos of asset leverage and optimal capital utilisation. However, if the resource input is critical its acquisition may be the optimal decision.

Return spread (ROCE/Cost of Capital) and Risk Profile Assessment: is linked to the previous topic. The return spread is simply the margin difference between the return on capital employed generated by an organisation and the cost of the capital used to produce the result: Clearly asset leverage can increase this measure.

Magretta suggests more than an innovative approach to process management. The successful business model not only identifies, and differentiates between, the industry critical success drivers (knowledge management, technology management, process management and relationship management) but also uses them to create effective and efficient methods of building value for customers by linking them with the value drivers that are important to customers. While enhancing value and, this simultaneously extends the organisation's competitive advantage.

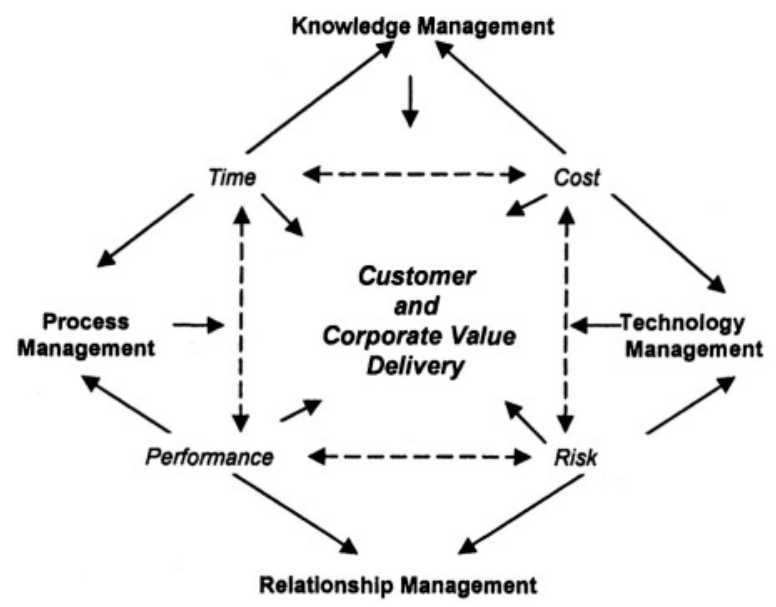

Figure 1: Integrating Strategic and Customer Value Drivers 
Some examples explore this in more detail. Caterpillar is conscious of end-user customer performance expectations. Caterpillar customers typically operate in remote locations, often at a considerable distance from service support facilities. Product failure can be financially damaging. To meet the need for availability the Company has used technology management to develop "remote diagnostic" equipment that when fitted to wear-sensitive components, gives prior warning of the approaching need for replacement. Electronic communications alert Caterpillar and the distributor service network of the problem. The response is very rapid with service parts and engineers despatched immediately.

"Logistics specialists" are using GPS systems to track the progress of "perishable" cargoes while remote controlled sensors and monitors control container climatic environment. This use of technology management has a twofold impact. Performance is increased as delivery times and product quality are maintained and cost (by eliminating wastage) is reduced. Figure 1 models the interrelationships between industry success factors and customer value drivers.

\section{CONCLUDING COMMENTS}

Much is being written concerning the benefits of the virtual community/value chain approach. However there are not many contributions concerning how the issues and concerns the approach creates may be resolved and how the concept may be transferred into reality. McHugh et al have identified the important characteristics if the approach is to be successful. An integrator has one of two functions (and may well perform both): one is to provide the initial 'strategic vision' around which the virtual organisation is structured: the other is a coordinating role within the virtual enterprise/value chain, identifying, matching and directing resources. However this and other contributions have yet to deal with the detail of applying the concept. In this paper we have attempted to initiate this task by identifying major issues and concerns and to introduce a framework within which this may take place. Clearly there is more to be done.

\section{REFERENCES}

Best R , Market Based Management, Prentice Hall, New Jersey, 2004

Campbell, A, "Creating the virtual organisation and managing the distributed workforce", in Jackson P and Van der Weilen J (eds), New Perspectives on Telework - From Telecommuting to the Virtual Organisation, Report on workshop held at Brunel University, 1996

Champion D, "Mastering the Value Chain", Harvard Business Review, June 2001

Hergert M and D Morris, "Accounting Data for Value Chain Analysis", Strategic Management Journal, 10,1989

Kay, J, Foundation of Corporate Success, OUP Oxford, 1993

Macmillan, I C and McGrath, R G, "Discovering New Points of Differentiation", Harvard Business Review, July/August, 1997.

Magretta J, "Why Business Models Matter", Harvard Business Review, May 2002

McHugh, P, G Merli and G Wheeler III, Beyond Business Process Reengineering, Wiley, Chichester, 1995

Neely A, C Adams and M Kennerley, The Performance Prism: The Scorecard for Measuring and Managing Business Success, FT Prentice Hall, London, 2002

Normann R, Reframing Business, Wiley, Chichester, 2001

Shank J and V Govindarajan, Strategic Cost Management: The New Tool for Competitive Advantage, The Free Press, New York, 1993 